\title{
USED TIRE AS BASE ISOLATOR TIRE FOR EARTHQUAKE RESISTANT HOUSES
}

\author{
Inggemar Särfors ${ }^{1}$
}

\begin{abstract}
The investigation of foundation on tires for absorbing the earthquake energy on houses structure is described here. The foundations are cut cone in shape. There are two tests have been conducted to investigate the shaking energy absorption. First, the foundation is placed on the sand filled tire. The second one, the double tires support round foundation. For comparison purpose, the foundation on sand test without tire is also conducted. The laboratory tests are performed using double hydraulic jack to generate the applied loads. The first jack is used to give the vertical load on the top of foundation to simulate the house load. The other jack is used to produce the load in the horizontal direction to replicate the earthquake load. The results of the tests are plotted in the terms of horizontal load and displacement corves. The double tires foundation shows the higher horizontal displacement-load ratio compared to the others. It indicates that the double tire based foundation absorbing the earthquake energy better than the others. It is concluded that the tired based foundation can be installed to support in the earthquake resistant houses.
\end{abstract}

Keywords: foundation, earthquake resistance, base isolation

\section{BACKGROUND}

The Andalas University has played a major lead role in the damage assessments and reconstruction guidelines after the West Sumatra earth quake in September 2009. Many research focused on behaviour of dynamic resistant of the ordinary houses has been initiated. To strengthen the future research, recently a dedicated Seismic Research Center in the Civil Engineering department has been established.

In this university, the shake table ( $2 \mathrm{~m} \times 3 \mathrm{~m})$ mimics the horizontal ground acceleration of an earth quake and sensor devices send records of the movements to a computer have been set up. Beside the dynamic load test, horizontal push over tests on a structure or an element of structure also have been conducted. In the future, the tests of dynamic loading of tire-base-foundations are conducted using the shake table.

When a big earth quake attaches a house, many possibilities can happen. It the house strong enough to the earthquake, then nothing happen and loss of human lives can be avoided. But if the house is in very bad condition as many houses in the earth, it can be broken or some of material waste could be felt down and be dangerous to the human under it.

In many countries such as Japan and USA with top of the line seismic mitigation technology, there are sophisticated isolator devices in the foundations that provide this preventive protection from the earthquake attach. Roller bearings on bowl-shaped steel dishes or neoprene rubber cushions separate the violent shock waves in the ground from the building foundations. Needless to say these technologies are too expensive for the majority of potential earth quake victims in the world, especially for ordinary people.

\footnotetext{
${ }^{1}$ Architect of Saevfor Consulting, Sweden
} 
Fortunately, in developing countries similar principles could be expanded using local materials with alternative design approaches. However, up to now not much attention has been devoted to such solutions by the international development community. Apart from the earth quake risk reduction achieved at a much lower cost there could also be considerable employment opportunities generated for unskilled people.

After the earth quake in West Sumatra, September 2009, the idea came to mind to use old car and motor cycle tires as shock absorbers. It turned out that these waste products do not have any particular value, not even in the informal sector (Figure 1). Being mainly an environmental health problem as mosquito breeding deposits a synergy effect could then be achieved if used as construction materials in the foundations. Another advantage would be the reduction of fire risks, once ignited rubber fires are extremely difficult to fight.

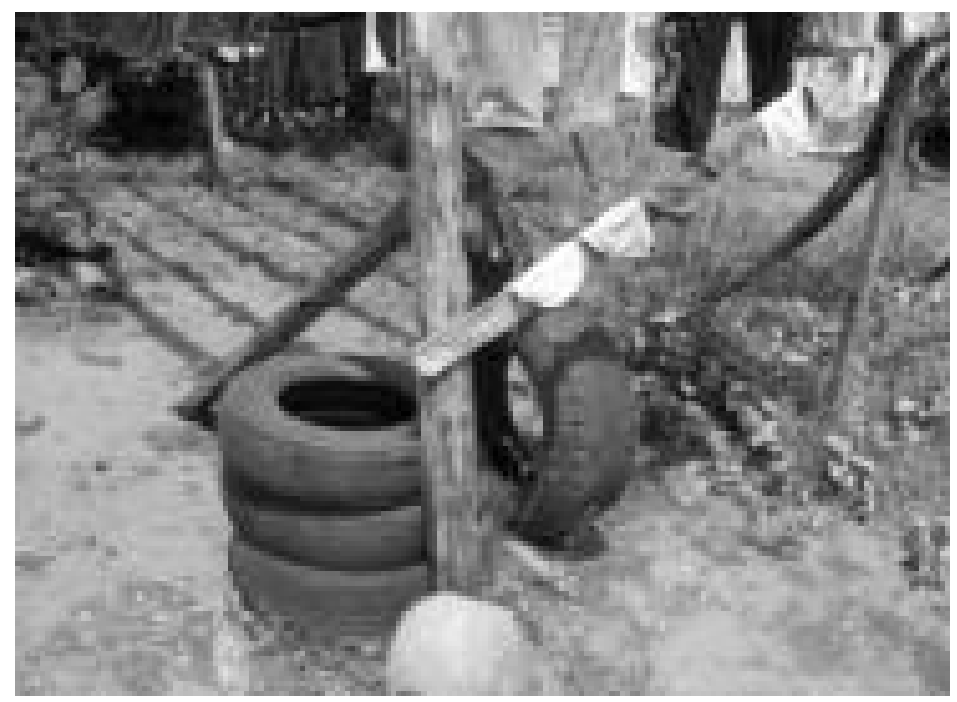

Figure 1. Disposal of Used Tires (by Saevfors, 2010)

\section{ELEPHANT FOOT ON A TIRE}

In order to take advantage of old tires as shock absorbers, a step in the ongoing research on low cost seismic base isolators for house foundations has been initiated in cooperation with Andalas University. The idea was to test a single unit of the "elephant foot on a tire" concept with a vertical load (about 2 ton for a real house) to represent the proportional weight of a brick house. (For more background details, see files available at www.saevfors.se).

The use of tires as shock absorbers is based on the practical experiences as follow:

a. In many harbors there are old tires hanging on the quay sides as fenders to reduce the shock when a ship hits the dockside.

b. In car races, piles of tires are used for spectators to protect against crashing vehicles.

c. When blasting rocks in open air, mat assemblies of cut tires are used to protect against undesired destruction effects.

Previously Luleå Technical University (LTU) in Sweden, has already a solid knowledge of recycling rubber waste, mainly in the form of shredded tire mixed with soil aggregates. This technology is mainly used for road banks in Sweden. Hence the environmental consequences of

\section{8 | J URNAL REKAYASA SIPIL}


long term underground use of tire rubber are already well known. Luckily the pollution risks for ground water etc. are negligible.

The hardening, cracking and final defragmentation of tires visible on vehicle churchyards are primarily due to the ultraviolet radiation from the sun. This process could be totally avoided if the tires are buried in a foundation trench. Even it has not been investigated yet, base on the experience that the buried rubber under the ground still can endure for years. Other development and research made in this field focus also on mixing rubber particles with soil. Some of these concepts are targeting foundations of large buildings.

In construction, however, the direct use of tires, as they are, is an idea apparently not yet explored. One reason could be the presumed stability issues and the potential problems of cracking walls associated with a moving foundation on flexible rubber. However these issues could also be addressed in an alternative design allowing for dilatation joints for example. These are after all secondary problems of merely esthetics compared to the massive devastation of an earth quake. Then the stability of 'one piece' house on a shaking must be the final target of the many steps research on Earthquake Resistant Houses on Used Tires (Figure 2).

Here, the proposal of "Elephant foot on a tire", is designed to be integrated with the brick construction practice in Indonesia. The earthquake norms prescribe a robust configuration of reinforced concrete columns and beams to confine the brickwork and make the house to jolt as one unit.

The prefabricated "Elephant feet" on tires could be merged into this system when the foundation beam is cast. The convex bottom face allows the "Foot" to center back to the car tire after each bump. The concept is based on locally available materials, simple tools and mainly unskilled labor. Local masons and craftsmen could be trained for supervision.

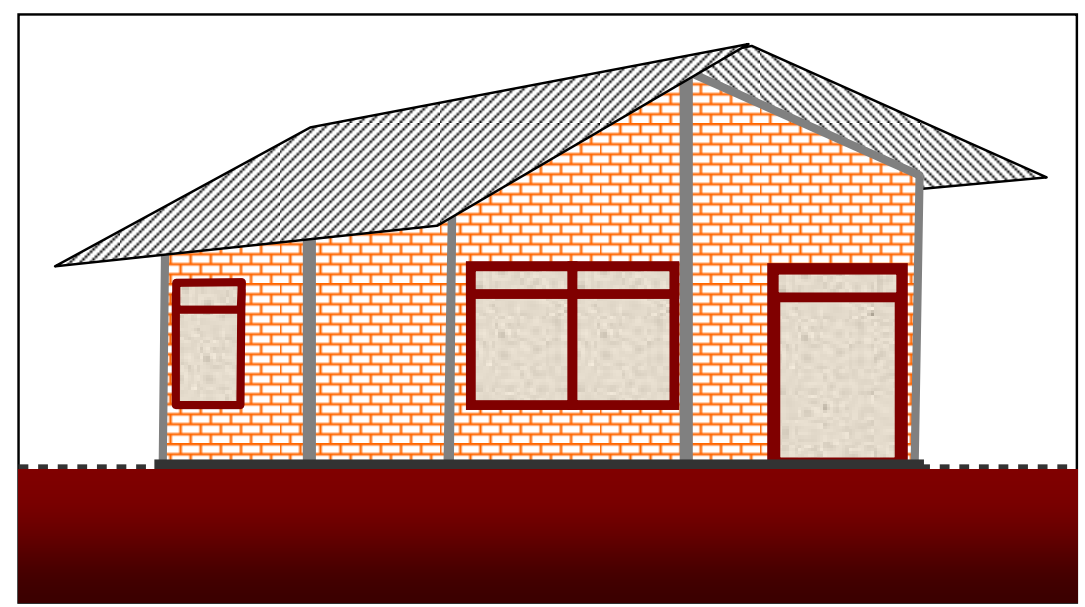

Figure 2. A house on tire-base-feet

\section{TESTS}

The preliminary design of the test of tire-base-foundation system is designed to observe the maximum force (both vertical and horizontal forces, and the combination of them) that can be supported by the system (Figure 3). The tire-base-foot is placed on the sand filled box. The thickness of the sand is $10 \mathrm{~cm}$. 


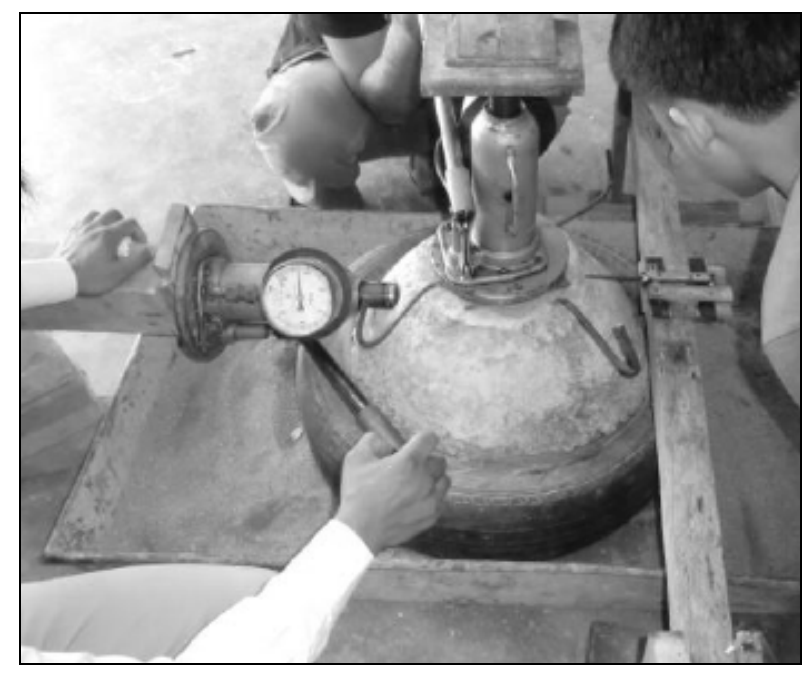

Figure 3. Tire-base-foot on sand (by Saevfors, 2010)

First, the applied vertical force is given by the use of hydraulic jack. The load is applied slowly and the vertical compression (settlement) of the tire is monitored. The applied load is topped when the tire is completely flat and the vertical force is referred as the maximum one (Figure 4).
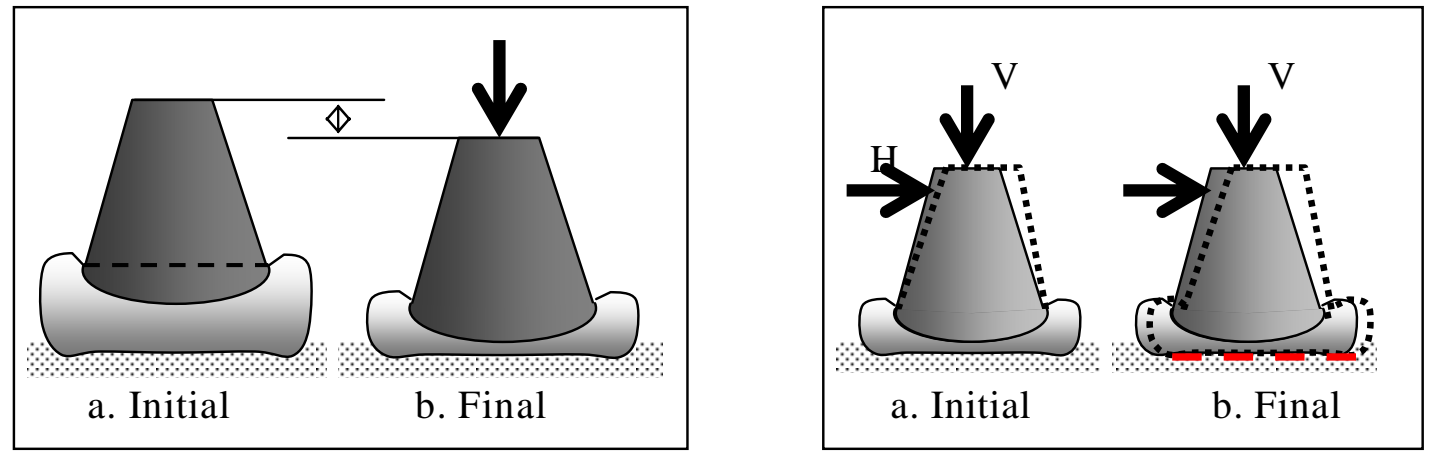

Figure 4. Vertical and push over test of the foot

Then, under the maximum vertical force, the horizontal force are slowly applied. The horizontal displacement during the loading is recorded. The collapse of the tire-base-foot system is considered if the movement (horizontal displacement) of the system is propagated by the slip of the contact surface between the tire and the sand. The same way (push over test) is adopted to the double-tire and no-tire base foundation. The force-displacement graph of horizontal force each test can be sketched from the tests.

\section{RESULTS}

\subsection{Vertical Loading}

The test results of vertical force shows in Table 1. The vertical compression (settlement) on the tires for single tire resulting about a third of that doubles one. For single tire, the flat tire occurred with the maximum force of $2000 \mathrm{~kg}$. The double tire system gave more settlement that is about 
twice of single tire one but the maximum vertical force just only $700 \mathrm{~kg}$. The test result for single and double tire with vertical load shows that the more tire used as foundation base, the less vertical bearing capacity resulted.

Table 1. Maximum Vertical Load

\begin{tabular}{|c|c|}
\hline Base type & Maximum Vertical load \\
\hline Single-tire & $2000 \mathrm{~kg}$ \\
\hline Double-tires & 700 \\
\hline
\end{tabular}

\subsection{Horizontal Push Over}

The first push over test applied to the single-tire base foundation is shown in Figure 5. The applied horizontal linearly increases till it reach the force of $600 \mathrm{~kg}$. Beyond this point, the displacement of the foundation happened on the tire-foundation system. After this point, the sliding on the contact surface between the tire and sand initially occurred. The sliding surface keeps on going as the horizontal force is continuously applied that indicates the slip failure has occurred.

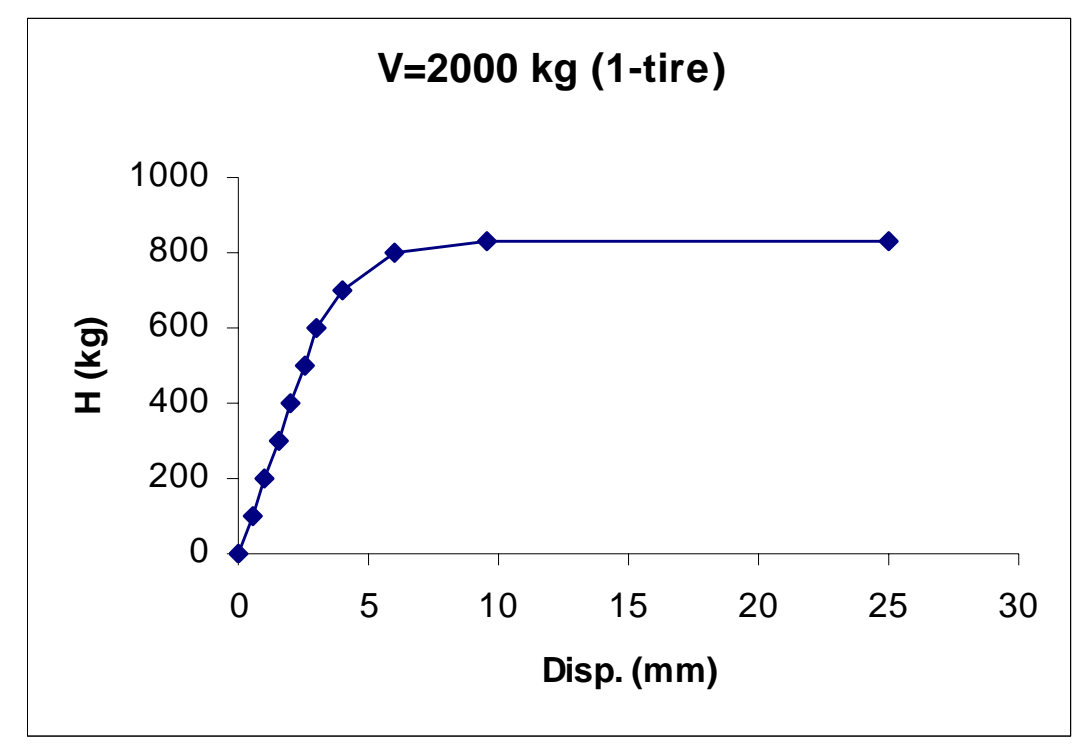

Figure 5. Push Over Test of The Single-Tire Foot

The push over test result for double tire with vertical load of $700 \mathrm{~kg}$ is shown in Figure 3. The test gives different result to the previous one. In the beginning of the push over test, it shows non-linear behavior in term of horizontal-displacement curve. The slip failure on the contact surface between the tire and sand happened about $300 \mathrm{~kg}$ of horizontal force, that is less than a half of single-tire one. However, the displacement on the tires is about three times compared to the single-tire. It indicates the advantage of the use of the tire to dissipate the horizontal energy. The push over energy is converted to the displacement without any failure on the foundation. In case of isolated foundation, the tire can role as the absorbed energy (Figure 6.) 


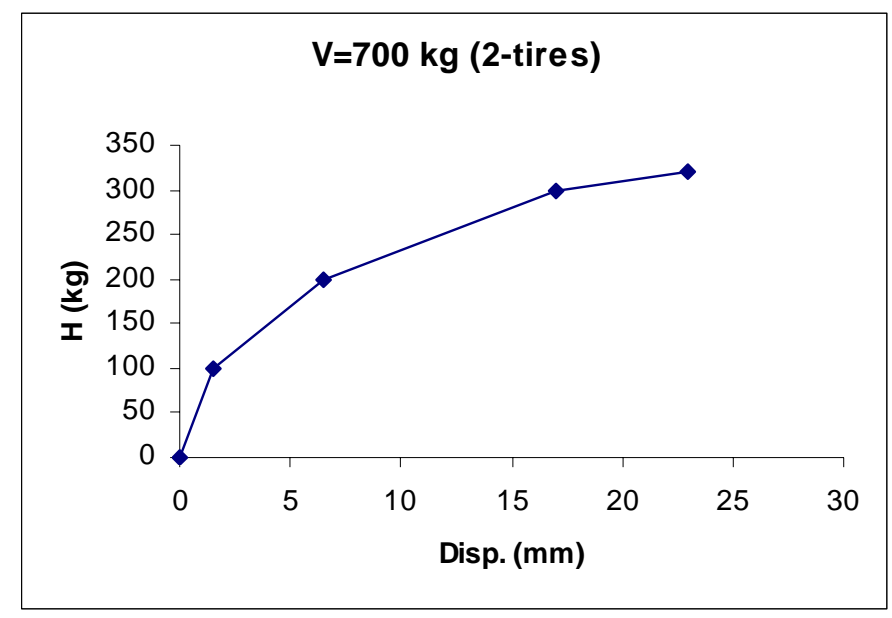

Figure 6. Push Over Test of The Double-Tire Foot

The last of this series test is the push over of elephant foot on sand. The foot is placed on sand directly without any tire, then vertical load are jacked. The vertical load is given only $2000 \mathrm{~kg}$ to see the behavior of the foot without tire. Then the horizontal force is pushed on the top of footing in the same way as previous tests. The test result for this type of foundation is shown in Figure 7. The horizontal load - displacement curve has a peak before it goes to its residual strength (slip). This behavior is very different to the results test of feet on tires. The important thing recognized from this result is that the slip on contact surface between footing and the sand happens as soon as the horizontal force is applied. The maximum displacement at the final push over force is about 10 $\mathrm{mm}$.

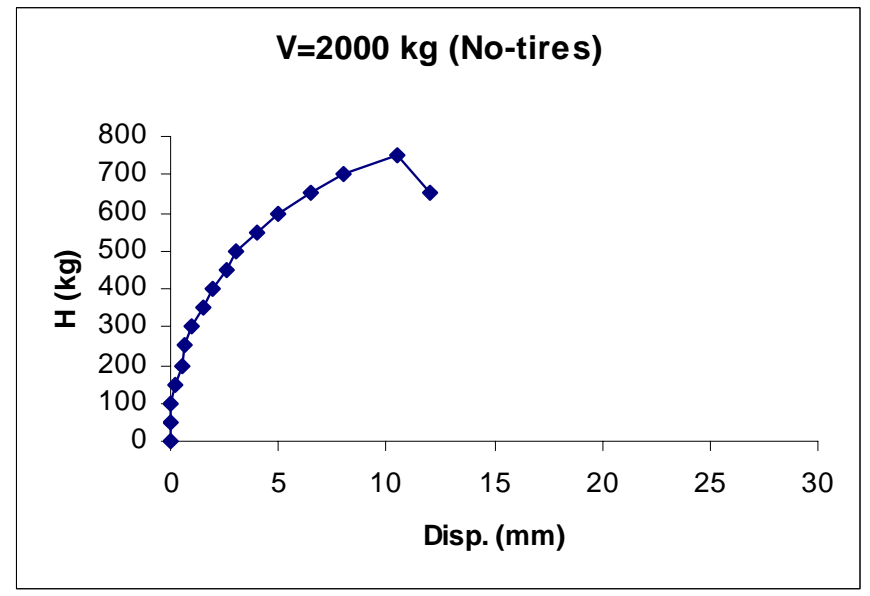

Figure 7. Push Over Test of Foot on Sand

Figure 8. shows the plot all tests of the foundation models in the same graph. Clearly understood that the bigger vertical load given, the higher maximum horizontal force is formed. It shows that there is a relation between vertical load on footing and its horizontal resistance. 


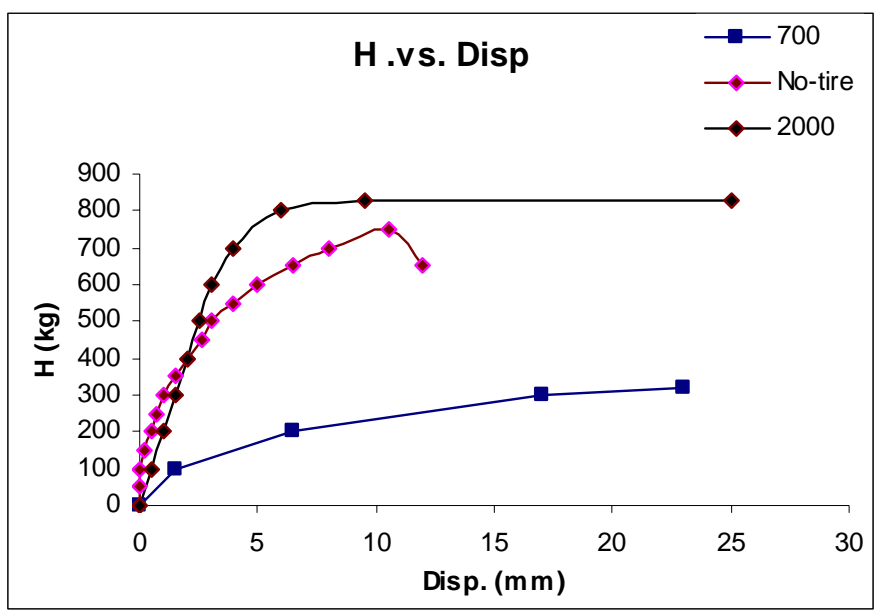

Figure 8. Push Over Test of Elephant Feet

The normalization horizontal forces compared to the maximum load applied to each model is shown in the Figure 9. First, it can be seen that the horizontal force-load curves from feet on tire (single and double) have low slope compare. It may happen due to the effect of the rubber tire under the foundation. The second point is that for $2000 \mathrm{~kg}$ foot on tires has push over strength higher than the food on sand. It may indicate that the tire contribute to the sliding strength of the feet. The sliding strength in contact surface sand-rubber is higher compared to the sand-footing (concrete).

\section{OBSERVATIONS}

Base on this initial test of footing on tire base as the absorbed earthquake energy for houses, there are some points can be drawn:

a. The quality of the used tires may play a major role. The initial tests in Sweden to check the general rubber resistance to compression, it can be provided the winter specification tires at hand. Although used and deemed to be no longer suitable for cars, these were obviously of much higher quality than regular worn out Indonesian tires. For the next test phase a selection from a good number of used tires would certainly make a difference in performance as the there is a considerable variation in quality of tires in Indonesia. Even the better used tires still have economic values.

b. Even so, with the low quality of these random tire samples, the displacement at an earth quake corresponding to a $0.5 \mathrm{G}$ acceleration, would allow for an important dissipation of the shock wave energy. Hence the searched shock absorber effect is achieved.

c. The comparatively higher displacement of the tires without sand filling is here an advantage if we consider the ground moving under the building. The displacement allowed by the rubber material reduces the shock movements transferred to the building more significantly.

d. The reason for applying two layer tires in test was again the low quality of the samples. One tire alone would probably not have sustained the weight and would have caused a touchdown of the elephant foot, thus spoiling the isolator effect.

Next steps to be done to complete the research on shake absorber in used of tire are:

a. An enlarged test phase to have a statistically more solid basis.

b. Prequalification of used tire samples prior to tests. The large quantities available would prevent a negative price effect. 
c. Shake table tests of a 4 unit, self stabilized Elephant foot configuration.

d. Test of the "Rolling stones effect", as initially designed. Round river stones under the elephant foot could work as roller bearings in the bottom of the foundation (Figure 9.)

e. Building of demo prototype houses.

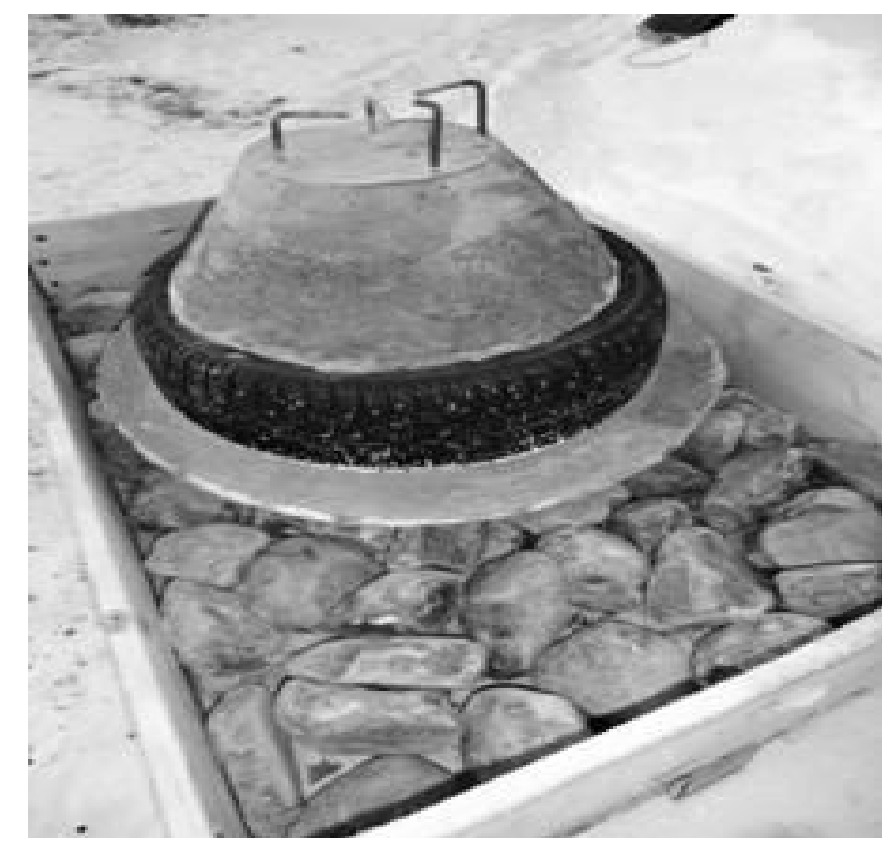

Figure 9. Rolling Stones Effect of Footing

\section{REFERENCES}

Ingemar Saevfors, (2010)a, "Seismic Shock Absorbers From Used Tires”, 21-29 May 2010, http://www.saevfors.se.

Ingemar Saevfors, (2010)b, “Tests on Seismic shock absorbers from used tires: Draft Version”, August 27, 2010.

http://www.youtube.com/watch?v=EFdO3kcMe_4

\section{J URNAL REKAYASA SIPIL}

